Article

\title{
Formulation of a Phenol-Rich Extract from Unripe Olives (Olea europaea L.) in Microemulsion to Improve Its Solubility and Intestinal Permeability
}

\author{
Lorenzo Cecchi ${ }^{1,+}\left(\mathbb{D}\right.$, Vieri Piazzini ${ }^{2,+}\left(\mathbb{D}\right.$, Mario $\mathrm{D}^{\prime}$ Ambrosio $^{3}$, Cristina Luceri $\left.{ }^{3}{ }^{(}\right)$, \\ Federica Rocco ${ }^{1}$, Marzia Innocenti ${ }^{1}$, Giulia Vanti ${ }^{2}{ }^{\mathbb{D}}$, Nadia Mulinacci ${ }^{1}$ and \\ Maria Camilla Bergonzi ${ }^{2, *(D)}$
}

1 Department of Neuroscience, Psychology, Drug Research and Child Health (NEUROFARBA), Section of Pharmaceutical and Nutraceutical Sciences, University of Florence, via U. Schiff 6, Sesto Fiorentino, 50019 Florence, Italy; lo.cecchi@unifi.it (L.C.); fede.rocco12@gmail.com (F.R.); marzia.innocenti@unifi.it (M.I.); nadia.mulinacci@unifi.it (N.M.)

2 Department of Chemistry, University of Florence, via U. Schiff 6, Sesto Fiorentino, 50019 Florence, Italy; vieri.piazzini@unifi.it (V.P.); giulia.vanti@unifi.it (G.V.)

3 Department of Neurosciences, Psychology, Drug Research and Child Health (NEUROFARBA), Section of Pharmacology and Toxicology, University of Florence, Viale Pieraccini 6, 50139 Florence, Italy; mario.dambrosio@unifi.it (M.D.); cristina.luceri@unifi.it (C.L.)

* Correspondence: mc.bergonzi@unifi.it; Tel.: +39-055-457-3678

+ These authors contributed equally to this work.

Received: 16 June 2020; Accepted: 9 July 2020; Published: 13 July 2020

check for updates

\begin{abstract}
The beneficial properties of phenolic compounds from Olea europaea L. are well-known. An olive extract $(\mathrm{OE})$ was prepared from unripe olives (Moraiolo cultivar). The study aimed to formulate $\mathrm{OE}$ into a microemulsion (ME) in oral dosage form. OE was extracted from olives with EtOH: $\mathrm{H}_{2} \mathrm{O}(80: 20)$ and characterized by HPLC-DAD. ME composition was stated by a solubility and pseudo-ternary diagram. The ME was chemically and physically characterized, and its stability at $4{ }^{\circ} \mathrm{C}$ was analyzed for three months. The ability of the formulation to ameliorate the solubility and the intestinal permeability of OE was evaluated by a Parallel Artificial Membrane Permeability Assay (PAMPA) assay and Caco-2 cells. The total phenolic content of the extract was $39 \% w / w$. The main constituent was oleuropein $(31.0 \%)$, together with ligstroside $(3.1 \%)$ and verbascoside $(2.4 \%)$. The ME was prepared using Capryol 90 as the oily phase, and Cremophor EL and Transcutol (2:1) as surfactant

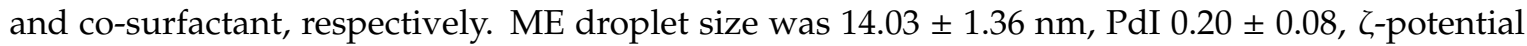
$-1.16 \pm 0.48$. Stability of ME was confirmed for at least three months. The formulation was loaded with $35 \mathrm{mg} / \mathrm{mL}$ of $\mathrm{OE}$, increasing the solubility of the extract by about four times. The enhanced permeability of OE was evaluated by PAMPA, as demonstrated by the Pe value $\left(1.44 \pm 0.83 \times 10^{-6} \mathrm{~cm} / \mathrm{s}\right.$ for OE hydroalcoholic solution, $3.74 \pm 0.34 \times 10^{-6} \mathrm{~cm} / \mathrm{s}$ for OE-ME). Caco-2 cell transport studies confirmed the same results: $\mathrm{P}_{\text {app }}$ was $16.14 \pm 0.05 \times 10^{-6} \mathrm{~cm} / \mathrm{s}$ for OE solution and $26.99 \pm 0.45 \times$ $10^{-6} \mathrm{~cm} / \mathrm{s}$ for OE-ME. ME proved to be a suitable formulation for oral delivery.
\end{abstract}

Keywords: Olea europaea L.; phenolic compounds; microemulsion; PAMPA; caco-2; oleuropein; hydroxytyrosol; permeability; ligstroside; verbascoside

\section{Introduction}

The beneficial health properties associated to a regular consumption of extra virgin olive oil (EVOO) and other food products derived from the olive tree (Olea europaea L.) are well-known, mainly thanks to the presence of specific phenolic compounds. For these reasons, natural remedies against 
diseases, nutraceutical ingredients, and food supplements based on phenol-rich extracts from different parts of the olive tree have been proposed for the protection of people's well-being [1-4].

The main phenolic compound present in the olive fruits is the secoiridoid oleuropein, followed by other secoiridoids, namely ligstroside, nuzhenide (only present in seeds), and demethyloleuropein (which appears in late ripening stages), and by the phenylpropanoid derivative verbascoside [5-8]. Their concentration is affected by ripening stage and the part of the fruit [5,9-11]. Oleuropein reaches the maximum concentration (up to $14 \% w / w \mathrm{dm}$ ) in young fruits [10]. Then, during the green maturation, its level, as well as those of verbascoside and ligstroside, constantly decreases [5,12-14].

Several beneficial properties have been described for the main phenolic compounds present in unripe olive. Oleuropein showed potential antioxidant, anti-inflammatory, anti-atherogenic, anti-cancer, anti-viral, anti-aging, and neuroprotective properties [10,15-17]. Verbascoside, also known as acteoside or kusaginin [18], is a bio-active molecule well-known for its antioxidant, anti-inflammatory, antibacterial, antifungal, potential anticancer, and anti-tuberculosis properties [18-23]. In a recent study, ligstroside showed beneficial effects against Alzheimer's disease and the capability in expanding the lifespan and enhancing the cognitive function of aged mice in vivo [24].

The phytocomplex, that is a whole or partially purified extract of a plant constituent, offers greater efficacy and more advantages than a single isolated ingredient, thanks to synergistic interactions [25,26], and this is also true for the biological effects exerted by phenolic compounds from Olea europaea L. [26]. All this evidence makes dried unripe olives, very rich in verbascoside, ligstroside and, particularly, oleuropein (up to $10 \% w / w$ ) and total phenolic content (up to $18 \% w / w$ ), a very interesting raw material for preparing a new ingredient for food supplement very rich in phenols from Olea europaea L. [27]. This is especially true if olives are harvested at a very early stage, before any stone lignification, with this fact making the fruit easy to mince in order to obtain the ingredient.

Oleuropein and ligstroside are absorbed and subjected to phase-II metabolism in humans and then they are extensively metabolized to yield many other metabolites whose specific role in the biological properties attributed to oleuropein and ligstroside are yet to be clarified [16]. A study on rats supplemented by a phenolic extract of olive cake, suggests that these molecules and their metabolites are widely distributed in multiple organs or further metabolized [28]. The high correlation found in plasma among the metabolites of hydroxytyrosol (glucuronide and sulfate) and of oleuropein aglycon glucuronide was suggested as indicative of a variable efficiency of gastric hydrolysis in each individual [16]. The exposure to hydroxytyrosol resulted in a significant degree from ingested oleuropein aglycone contained in EVOO [17]. In terms of gender research, it has been pointed out that hydroxytyrosol metabolism is more efficient in female than in males [29].

Novel nanoformulations based on drug delivery systems are designed with the aim of enhancing bioavailability, solubility, physicochemical stability, intestinal permeation, resident time in the gastrointestinal tract, and controlled release of natural products [30-32].

In a recent study, zwitterionic liposomes containing phenols from Olea europaea L. were characterized for increasing phenols' bioavailability, but standards and not extracts were used [33]. Other studies, dealing with preparation of liposomes [34], W/O emulsion, microemulsion [35], and mPEG-PLGA nanoparticles [36], only focused their attention on hydroxytyrosol, while other ones focused their attention on extracts from olive leaves [37]. However, to the author's knowledge, no studies have investigated on the possibility to incorporate the phytocomplex of unripe olives in a drug-delivery system.

Amongst the various drug delivery systems, the microemulsion (ME) is considered an ideal alternative for the oral delivery of olive extract. ME is able to transform the dried extract into an oral dosage form to overcome the limited oral bioavailability, thereby increasing the therapeutic efficacy of the extract. Oil in water microemulsions have been formulated with food acceptable components to increase the solubility, stability, and ameliorate the intestinal permeability of the extract's constituents [38-40]. Additionally, several excipients used in these systems, including Cremophor, Tween 80, Labrasol, and Transcutol, could inhibit the function of P-gp [41-43]. Usually, 
the permeability of a compound or of a series of compounds present in an extract or formulation is assessed using cell cultures, and the Caco-2 monolayers models are the most widely used so far [44-46]. However, the long cell growth cycle and the high costs limit its use as a high throughput tool. For this reason, other models aimed to simulate gastrointestinal permeability, maintaining a good correlation with the in vivo permeability but with lower costs, have been developed using artificial membranes. The most used of this type of in vitro assay is the Parallel Artificial Membrane Permeability Assay (PAMPA) [45,47-49]. Recently, the PAMPA model has also been successfully used and validated for testing the permeability of bioactive compounds from extracts of several species and their formulations (e.g., Vitex agnus-castus, Silybum marianum, Chenopodium quinoa, Trigonella foenum-graecum, and Posidonia oceanica) $[45,49-51]$.

This study aimed to prepare a suitable and cheap drug-delivery-system to improve the bioavailability of phenolic compounds present in extracts from Tuscan unripe olives (cv Moraiolo) harvested before any stone lignification. A phenol-rich extract (OE) was prepared from freeze-dried olives using a hydroalcoholic solvent, and was characterized by HPLC-DAD. The more suitable ingredients of ME were selected after the solubility study in different vehicles. ME was chemically and physically characterized with DLS and HPLC-DAD analyses to evaluate the size, homogeneity, morphology, and encapsulation efficiency. Its stability was tested over three months and the permeation and transport studies were performed to determine the suitability of the formulation for oral delivery. Different in vitro models were applied, such PAMPA [47,51] and Caco-2 cell transport experiments.

\section{Results and Discussion}

\subsection{Phenolic Composition and Solubility in Different Vehicles of the Phenolic Extract}

The phenolic composition of the olive extract was characterized using a chromatographic approach already applied in our studies for analyzing the phenolic fraction of olives and derivatives [52,53], but avoiding the use of the internal standard. Consequently, the quantitative analysis was carried out using external calibration curves, instead of the internal standard method applied in the above cited papers that required the addition of syringic acid (ISTD) during the preparation of the OE. The presence of a molecule other than those naturally present in the extract would have interfered with and modified the final results of the study. The phenolic composition of the OE is reported in Table 1, while Figure 1 shows the phenolic profile of the OE (Figure 1A) and the chemical structure of the quantified phenolic compounds (Figure 1B).

Table 1. Phenolic composition of the olive extract. Data are expressed as the mean \pm SD from three independent determinations.

\begin{tabular}{cc}
\hline Compound & Extract $(\mathrm{mg} / \mathrm{kg})$ \\
\hline hydroxytyrosol $(\mathrm{mg} / \mathrm{kg})$ & $5424.7 \pm 270.8$ \\
tyrosol $(\mathrm{mg} / \mathrm{kg})$ & $655.2 \pm 46.4$ \\
rutin $(\mathrm{mg} / \mathrm{kg})$ & $6535.5 \pm 286.6$ \\
luteolin-7-O-glucoside $(\mathrm{mg} / \mathrm{kg})$ & $1696.2 \pm 613.6$ \\
verbascoside $(\mathrm{mg} / \mathrm{kg})$ & $23786.9 \pm 628.7$ \\
oleuropein $(\mathrm{mg} / \mathrm{kg})$ & $310187.5 \pm 2203.1$ \\
comselogoside $(\mathrm{mg} / \mathrm{kg})$ & $7399.8 \pm 738.2$ \\
ligstroside $(\mathrm{mg} / \mathrm{kg})$ & $31477.1 \pm 1375.8$ \\
\hline Total phenolic compounds $(\mathrm{mg} / \mathrm{kg})$ & $387162.7 \pm 4362.8$ \\
\hline
\end{tabular}




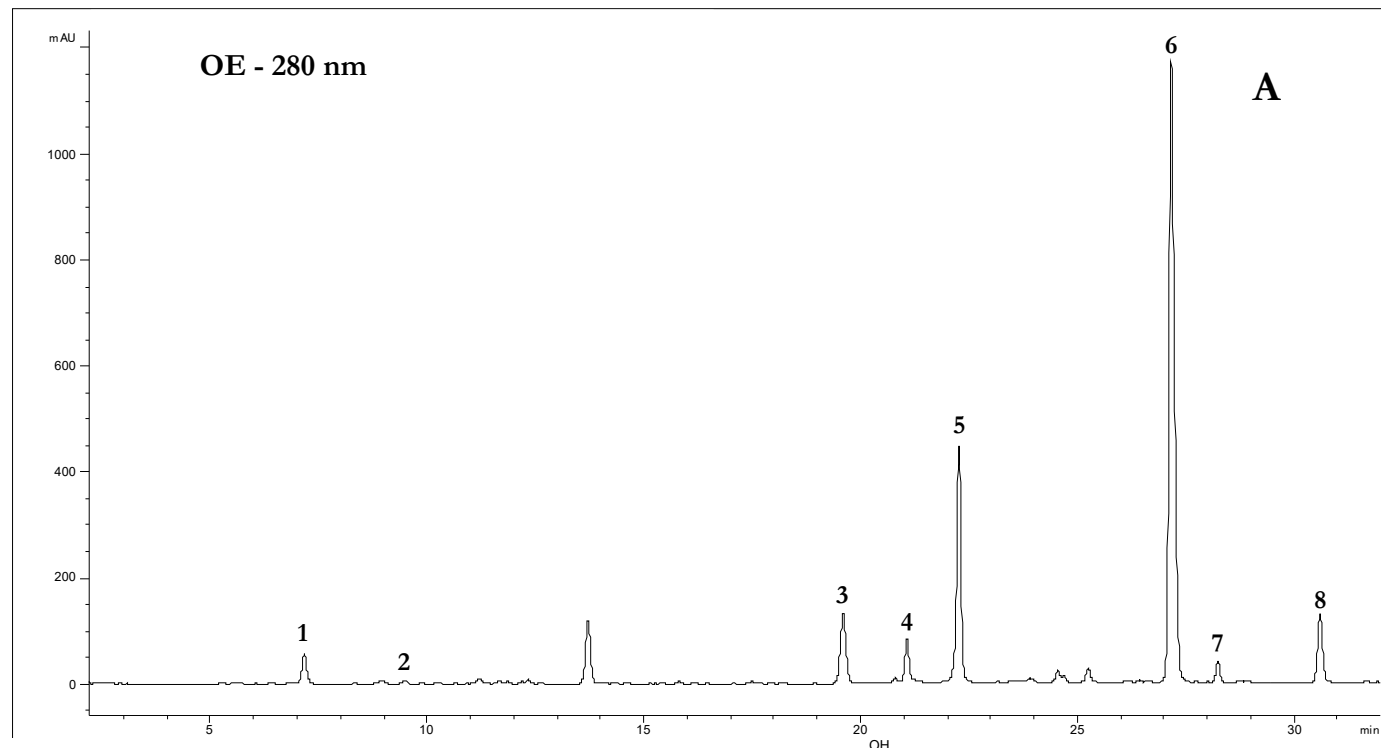

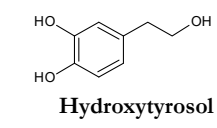
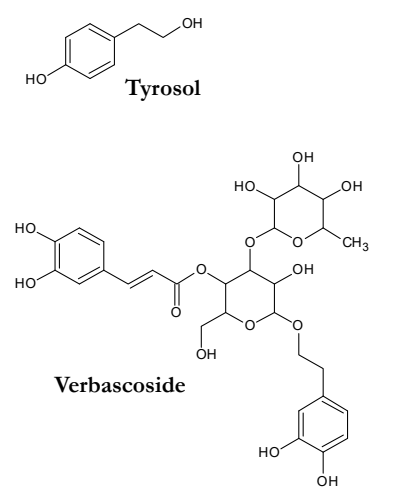

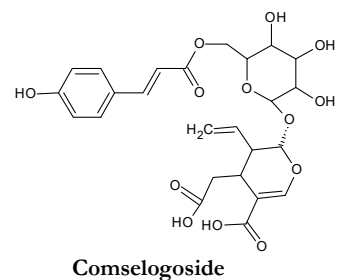

Comselogoside

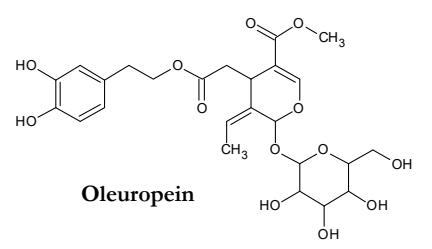

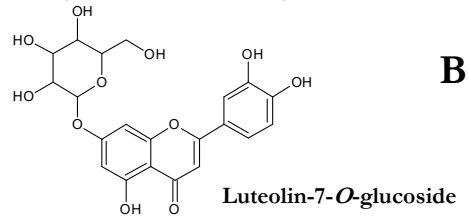

B

Figure 1. (A) Phenolic profile at $280 \mathrm{~nm}$ of the olive extract (OE). 1, hydroxytyrosol; 2, tyrosol; 3, rutin; 4, luteolin-7-O-glucoside; 5, verbascoside; 6, oleuropein; 7, comselogoside; 8, ligstroside. (B) The main phenolic compounds detected in the olive extract.

The concentration of total phenols in the OE is very high (approx. 39\% w/w). In particular, the highest concentrations were for oleuropein $(31.0 \% w / w$ of the weight of the extract, representing approx. $80 \%$ of the total phenolic content), verbascoside ( $2.3 \% w / w$, approx. $6 \%$ of the total phenolic content), and ligstroside ( $3.1 \% w / w$, approx. $8 \%$ of the total phenolic content). To the author's knowledge, the concentration of phenolic compounds in $\mathrm{OE}$ is higher than in other commercial extracts from Olea europaea L. As far as the widely used olive leaves extracts, some papers reported variable phenolic contents, usually lower than the values reached with the extraction of unripe dried olives selected for this study: in particular, oleuropein content was found in very low amounts, e.g., $0.077 \% w / w$ in a paper [54], and ranging from $2.1 \%$ to $20.4 \%$ in other papers [4,55-60], while the total phenolic content ranging $3.4 \%$ to $31.6 \%$ [ $4,56-60$ ], and reaching $38.4 \%$ only in one paper [55]. The typical phytocomplex of olive leaves is different from that of the $\mathrm{OE}$, which shows unique characteristics from both qualitative and quantitative points of view. The yields of the extract on the unripe olives weight ( $40 \%$, see Section 3.2) and the concentration of phenols per gram of extract are very high, and thus $\mathrm{OE}$ represents a new and interesting nutraceutical ingredient that could be used for the protection of 
people's well-being and to allow producers the possibility of diversifying their production, and thus new possibilities of income, in a period of the year when olive oil production has not yet commenced. Interestingly, the required amount of $\mathrm{OE}$ for the preparation of a microemulsion (see next paragraphs) can be obtained without negatively affecting the olive oil yields in a significantly way.

After the chemical characterization, solubility studies of olive extract were performed in water and in different surfactants and lipophilic solvents to select appropriate constituents for ME formulation. Table 2 shows that the vehicles differently affect the solubility of phenolic compounds, if compared with water: Captex 300, Captex 355, Labrafac, Labrafilm 1944, Labrafilm 2125, and Lauroglycol 90 showed a poor solubilization capability, while Transcutol, Labrasol ALF, and Cremophor EL showed the best solubilization capability, higher than water. Transcutol solubilizes a quantity of phenolic compounds that is approximately triple compared to water. These data suggest the possibility to strongly improve the solubility of OE phenolic compounds in comparison with pure water by using an optimized combination of the above vehicles in an ME.

Table 2. Solubility of the main phenolic compounds of the olive extract in different vehicles. Data are expressed as mean \pm sd from three independent measurements.

\begin{tabular}{ccccc}
\hline & $\begin{array}{c}\text { Verbascoside } \\
(\mathbf{m g} / \mathbf{m L})\end{array}$ & $\begin{array}{c}\text { Oleuropein } \\
(\mathbf{m g} / \mathbf{m L})\end{array}$ & $\begin{array}{c}\text { Ligstroside } \\
\mathbf{( m g} / \mathbf{m L})\end{array}$ & $\begin{array}{c}\text { Total Phenolic Content } \\
(\mathbf{m g} / \mathbf{m L})\end{array}$ \\
\hline Water & $0.243 \pm 0.007$ & $3.081 \pm 0.007$ & $0.314 \pm 0.003$ & $3.816 \pm 0.071$ \\
Capryol 90 & $0.060 \pm 0.009$ & $1.079 \pm 0.074$ & $0.115 \pm 0.001$ & $1.292 \pm 0.107$ \\
Captex 300 & nd & $0.058 \pm 0.012$ & $0.014 \pm 0.001$ & $0.074 \pm 0.013$ \\
Captex 355 & nd & $0.038 \pm 0.005$ & $0.012 \pm 0.001$ & $0.052 \pm 0.006$ \\
Labrafac & nd & $0.032 \pm 0.017$ & $0.007 \pm 0.003$ & $0.039 \pm 0.020$ \\
Labrafilm 1944 & $0.010 \pm 0.001$ & $0.411 \pm 0.007$ & $0.050 \pm 0.003$ & $0.483 \pm 0.002$ \\
Labrafilm 2125 & $0.010 \pm 0.001$ & $0.456 \pm 0.007$ & $0.070 \pm 0.022$ & $0.545 \pm 0.033$ \\
Labrasol ALF & $0.411 \pm 0.007$ & $5.331 \pm 0.010$ & $0.526 \pm 0.011$ & $6.582 \pm 0.057$ \\
Lauroglycol 90 & $0.018 \pm 0.004$ & $0.611 \pm 0.001$ & $0.069 \pm 0.002$ & $0.729 \pm 0.009$ \\
Transcutol & $0.702 \pm 0.007$ & $9.036 \pm 0.005$ & $0.896 \pm 0.025$ & $11.081 \pm 0.046$ \\
Cremophor EL & $0.326 \pm 0.040$ & $5.269 \pm 0.312$ & $0.510 \pm 0.047$ & $6.320 \pm 0.419$ \\
\hline
\end{tabular}

nd: not defined.

\subsection{Pseudo-Ternary Phase Diagram}

Based on the above results, Capryol 90 was selected as oil phase, and Cremophor EL and Transcutol as surfactant and co-surfactant, respectively. All the selected components have already been used and approved for oral administration purposes. Capryol 90 is propylene glycol monocaprylate and was already selected as oily phase in other studies due to its relative easiness of emulsification [61]. Capryol 90 has been investigated extensively as the oil phase for the development and optimization of nanoemulsions/microemulsions/Self-Nanoemulsifying Drug Delivery Systems (SNEDDS)/Self-Microemulsifying Drug Delivery Systems (SMEDDS) of various poorly soluble drugs both in vitro and in vivo [62]. Cremophor EL is a complex mixture of hydrophobic and hydrophilic components, with the main components being glycerol polyethylene glycol ricinoleate and glycerol ethoxylates, respectively. It had a very good ability to emulsify Capryol 90, as previously reported [61]. Transcutol is a hydrophilic co-surfactant and increases the spontaneity of the ME formation. It improves the emulsification of surfactants by penetrating the interfacial surfactant monolayer effectively, and it has a superior solubilizing potential performance. Cremophor EL and Transcutol were mixed at different ratios under vigorous stirring to obtain the surfactant mixture $\left(S_{\text {mix }}\right)$. Then, the pseudo-ternary phase diagram was constructed by the water titration technique, using different combinations of Capryol 90 and each $S_{\text {mix }}$. Figure 2 shows the obtained pseudo-ternary phase diagram. 


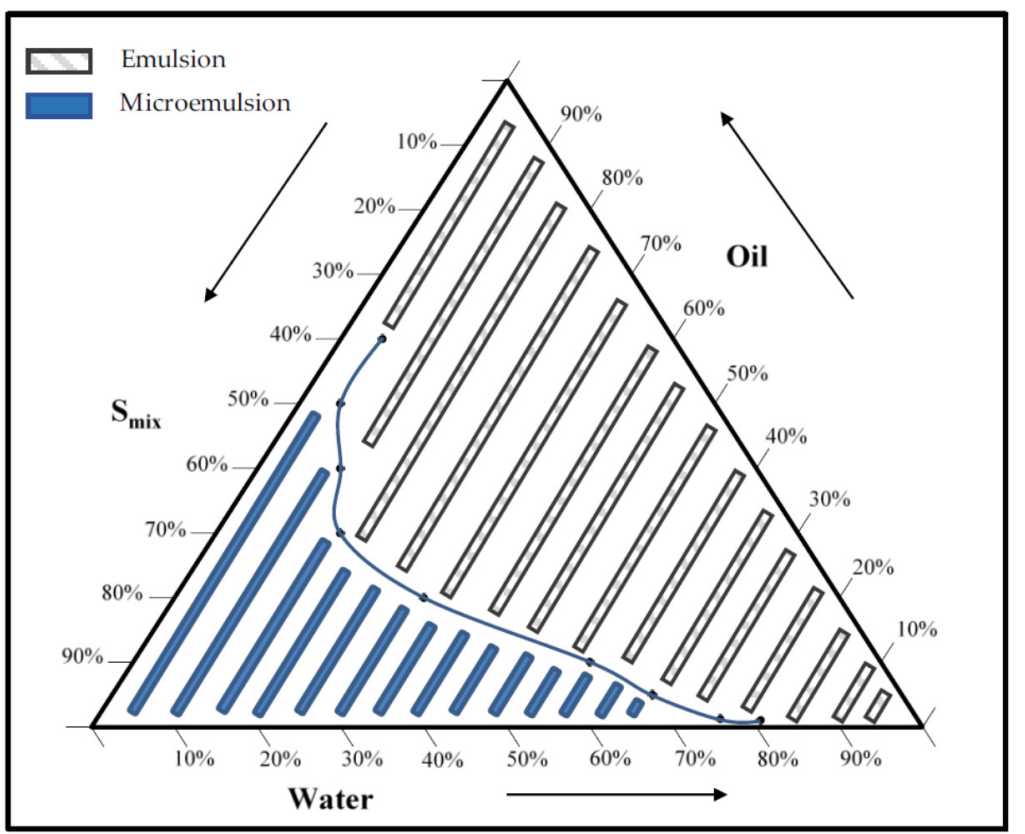

Figure 2. Pseudo-ternary phase diagram. The dark area represents the ME existence range and the grey area means crude emulsion range.

The final microemulsion was constituted by 1\% Capryol 90 (oil), 12.7\% Cremophor EL (surfactant), and $6.3 \%$ Transcutol (co-surfactant), in addition to water ( $80 \%)$.

\subsection{Solubility of Olive Extract into Microemulsion}

After the elaboration of a pseudo-ternary phase diagram, the maximum loading content of $\mathrm{OE}$ into the formulation was evaluated by adding an increasing amount of extract to the ME under stirring. The formulation was able to incorporate up to $35 \mathrm{mg} / \mathrm{mL}$ of OE, corresponding to $13.71 \pm 0.01 \mathrm{mg} / \mathrm{mL}$ of the identified phenolic molecules, without phase separation or precipitation of the extract. The OE is a hydro-alcoholic extract, partially soluble in water. It contains different phenolic compounds, mainly oleuropein, verbascoside, and ligstroside, with different structure and aqueous solubility. The ME increases the solubility of $\mathrm{OE}$ more than three times due to the presence of oil phase and tensides, which can also realize a micellar solubilization of the lipophilic compounds.

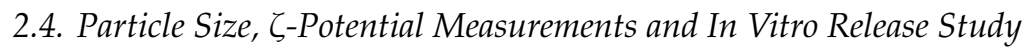

Empty and extract-loaded formulations were physically characterized by dynamic light scattering (DLS) and electrophoretic light scattering (ELS). The analyses confirmed the presence of a homogeneous system with narrow size distribution, low values of polydispersity index (PdI), and mean diameter (Table 3). The presence of the OE did not affect the physical properties of the system. ME showed very small particle size $(<100 \mathrm{~nm})$ which could promote the absorption by enterocytes and help to avoid the uptake by the cells of the reticuloendothelial system (RES) [63].

Table 3. Physical characterization of ME and olive extract-ME. Results are expressed as means \pm standard deviation of at least three experiments.

\begin{tabular}{cccc}
\hline Sample & Size $(\mathbf{n m})$ & PdI & $\zeta$-Potential $(\mathbf{m V})$ \\
\hline ME & $13.15 \pm 0.19$ & $0.14 \pm 0.01$ & $-1.23 \pm 0.17$ \\
OE-ME & $14.03 \pm 1.36$ & $0.20 \pm 0.08$ & $-1.16 \pm 0.48$ \\
\hline
\end{tabular}


Then, developed ME represents a successful tool to incorporate OE and to significantly ameliorate its solubility, in that it is able to solubilize $35 \mathrm{mg} / \mathrm{mL}$ of OE without destabilization of the system.

To further evaluate the appropriateness of the developed formulation for oral use, it is necessary to take into consideration the characteristics of the different environments that it can meet and the possible modifications of the loaded phenolic compounds. ME and hydroalcoholic solution $\left(\mathrm{EtOH}-\mathrm{H}_{2} \mathrm{O}\right.$ 70:30), both containing $35 \mathrm{mg} / \mathrm{mL}$ of extract, were compared and their behaviour has been taken into consideration to evaluate if the formulation could guarantee a prolonged release of the phenolic compounds. A first in vitro release study was carried out at the physiological $\mathrm{pH}(7.4)$, thus simulating the conditions that the formulation meets after its absorption (Figure 3). After $6 \mathrm{~h}$, the percentage of phenolic compounds released from ME (60.2\%) was lower than that obtained with the solution (75.9\%). A similar behaviour was obtained in simulated gastric fluid (SGF, Figure 4). By comparing the ME and solution, the release of the extract is more gradual and prolonged in the case of ME. It can be noted that, after $2 \mathrm{~h}$, the release of the extract by the solution corresponds to $32.6 \%$ of the phenolic compounds, while the formulation releases only the $14.0 \%$.

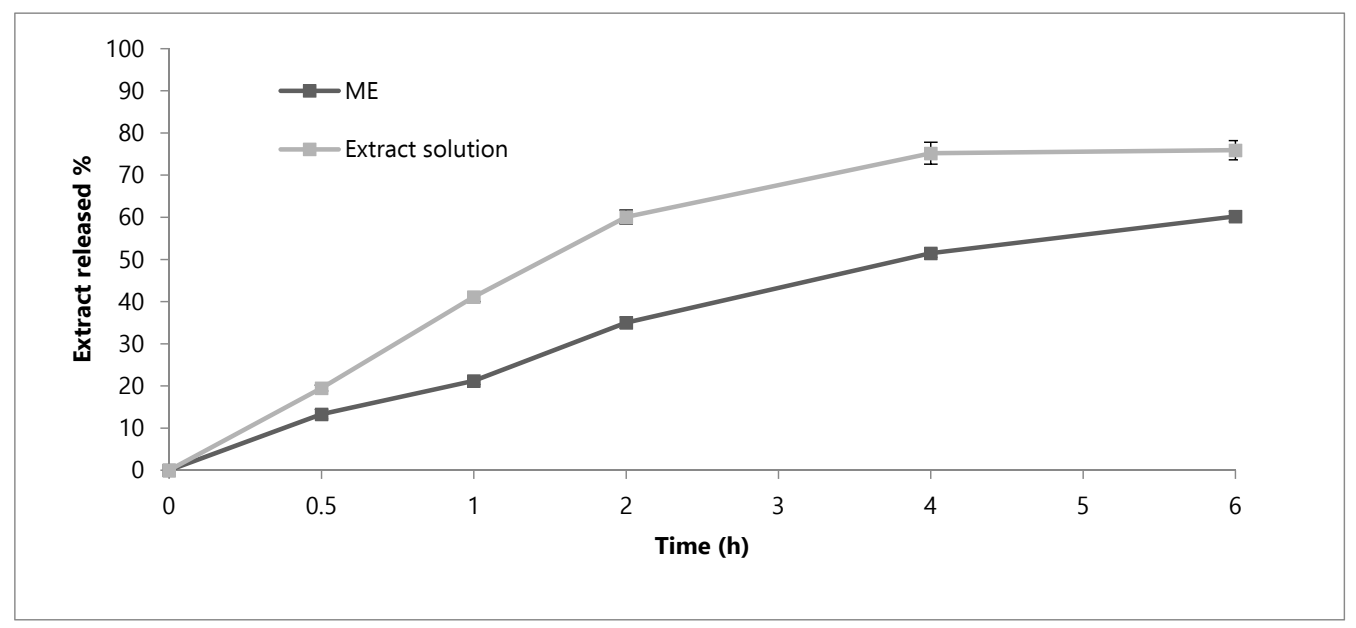

Figure 3. In vitro release profile of phenolic compounds from the OE-ME and OE ethanolic solution in Phosphate Buffered Saline (PBS) medium at $\mathrm{pH}$ 7.4. Each value is the mean $\pm \mathrm{SD}$ of three separate determinations.

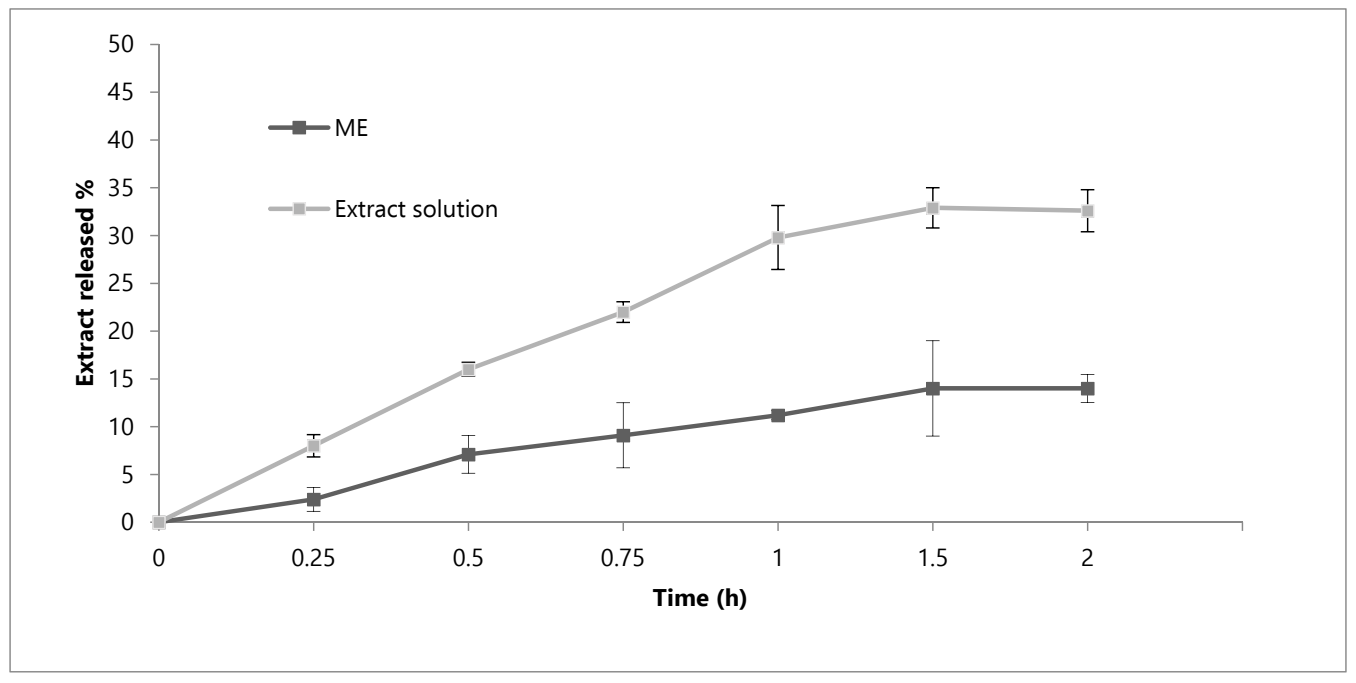

Figure 4. In vitro release profile of phenolic compounds from the OE-ME and OE ethanolic solution in Simulated Gastric Fluid (SGF) medium at $\mathrm{pH}$ 1.2. Each value is the mean $\pm \mathrm{SD}$ of three separate determinations. 
The last in vitro release study was carried out in the SIF at pH 6.8 (Figure 5) in order to simulate the intestinal transit. In a comparison between the two formulations, ME showed a more prolonged release than solution. In this case, the quantities of released phenolic compounds are greater than in the other two cases: after $6 \mathrm{~h}$, the percentage reaches $100 \%$ with the solution and $78.6 \%$ with the ME. Notably, in this condition, the release from the solution was $100 \%$ after $4 \mathrm{~h}$, while the release from the $\mathrm{ME}$ is still increasing after $6 \mathrm{~h}$, pointing to the capability of the ME to make the release much more gradual and prolonged than the solution.

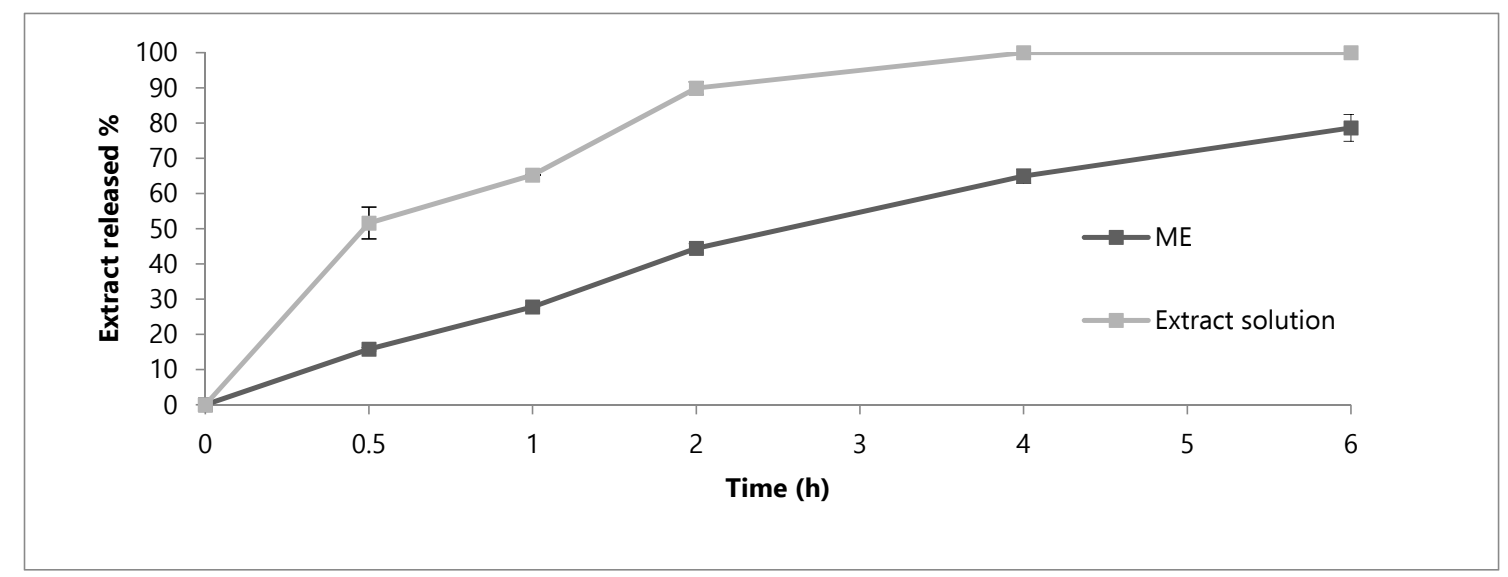

Figure 5. In vitro release profile of phenolic compounds from the OE-ME and OE ethanolic solution in Simulated Intestinal Fluid (SIF) medium at $\mathrm{pH}$ 6.8. Each value is the mean $\pm \mathrm{SD}$ of three separate determinations.

ME achieves a gradual release and protects the OE from degradation in the acid environment, because it releases a smaller quantity of phenolic compounds compared to the solution and compared to the amount released in the other two media, i.e., PBS and SIF.

\subsection{Chemical and Physical Stability During Storage}

In order to estimate the stability of the formulation, the OE-ME was stored in sealed glass containers at $4{ }^{\circ} \mathrm{C}$ for three months. Periodically, chemical and physical stability were checked by monitoring transparency, phase separation, colour variation, as well as the changes in particle size, homogeneity, $\zeta$-potential, and extract concentration by DLS and HPLC-DAD analyses.

The formulation proved to be stable during the whole duration of the test: no phase separation or creaming were observed. Moreover, size, homogeneity and $\zeta$-potential value resulted unchanged after 3 months: size $12.94 \pm 0.10 \mathrm{~nm}, \mathrm{PdI} 0.13 \pm 0.01,-1.10 \pm 0.01 \mathrm{mV}$. The concentration of phenolic compounds was $13.01 \pm 0.32 \mathrm{mg} / \mathrm{mL}$, corresponding to $95 \%$ of the starting amount. Moreover, the composition of the phenolic compounds was unchanged, with oleuropein ca. $80 \%$, ligstroside ca. $8 \%$, and verbascoside ca. $6 \%$. These findings evidenced the stability during the storage period of the developed formulation and the ability of ME to prevent the degradation of loaded compounds.

\subsection{In Vitro Parallel Artificial Membrane Permeability Assay (PAMPA)}

PAMPA represents a potential approach for the rapid assessment of passive transport permeability. PAMPA is performed to estimate passive transcellular permeability. It is a non-cell-based permeability model, but is considered robust, reproducible, and a helpful complement to the cellular permeability model for its speed, low cost, and versatility. A combination of the PAMPA and Caco-2 permeability model can synergistically provide invaluable permeability/absorption assessment of a drug. The assay could be applied not only in the pre-formulation studies of single molecules, but also to obtain information on the behavior of the extracts, and recently the authors applied the test to the study of compounds loaded into formulations, i.e., SLN, NLC, nanomicelles, and microemulsions $[15,45,64,65]$. 
The test was carried out in a 96-well, MultiScreen-IP PAMPA (Millipore corporation) filter plate. The ability of compounds to diffuse from a donor compartment into an acceptor compartment was evaluated. The $\mathrm{P}_{\mathrm{e}}$ of extract solution (EtOH:PBS 70:30) was $1.44 \pm 0.83 \times 10^{-6} \mathrm{~cm} / \mathrm{s}$ while the $\mathrm{P}_{\mathrm{e}}$ of OE-ME was $3.74 \pm 0.34 \times 10^{-6} \mathrm{~cm} / \mathrm{s}, p=0.0286$. The formulation improved the passive permeation of extract across the simulated membrane barrier. The permeability increases due to the increased solubility of the extract and the effect of penetration enhancers of the constituents of ME, in particular of Cremophor EL and Transcutol.

\subsection{Transport Experiments with Caco-2 Cells}

In order to complete the in vitro characterization of OE-ME, permeation studies were performed using a cell-based model. Caco- 2 cells are considered the most predictive in vitro model to estimate not only passive intestinal diffusion, as previously described for PAMPA, but also active transport processes, paracellular permeability, and active efflux [66,67].

To find the highest non/low toxic concentrations to be used in the transport experiments, the cytotoxicity of OE-ME was tested. For the MTS assay, the cells were incubated for 2 and $24 \mathrm{~h}$ at $37^{\circ} \mathrm{C}$ with fresh medium containing OE-ME. The results are shown in Figure 6.

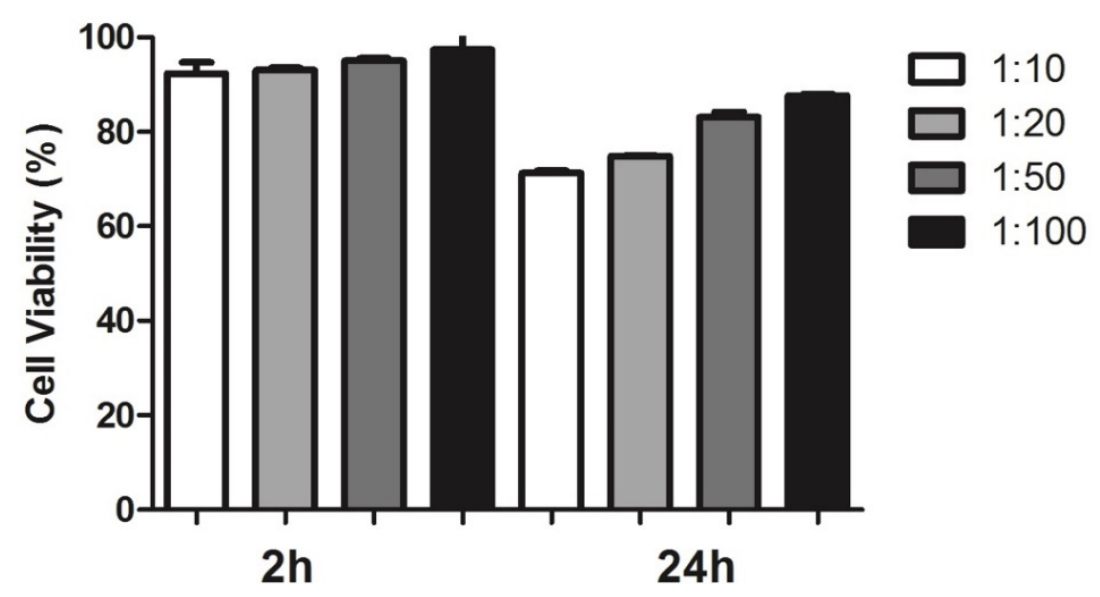

Figure 6. Viability of Caco-2 cells exposed to OE-ME (1:10 to 1:100), for $2 \mathrm{~h}$.

OE-ME loaded with $35 \mathrm{mg} / \mathrm{mL}$ of extract does not show any sign of cytotoxicity after $2 \mathrm{~h}$ of exposure, being the Caco-2 cellular viability close to $100 \%$ for all tested dilutions. After $24 \mathrm{~h}$, the cell viability percentage was still good: for ME diluted 1:100, it was up to $90 \%$ compared to untreated cells, confirming that the formulation and the extract do not affect cell viability. The dilution 1:100 was selected for transport experiments, considering that a cell viability $>80 \%$ is required for an acceptable in vitro assay [68]. In addition, the Lucifer yellow passage was less than $3 \%$, indicating the integrity of the layer [69].

Caco-2 cells were exposed to OE-ME 1:100 or OE at the same concentration present in the ME formulation ( $35 \mathrm{mg} / \mathrm{mL}$ ), for $2 \mathrm{~h}$, in the AP chamber, while the BL was filled with culture medium.

The $\mathrm{P}_{\text {app }}$ of the OE solution was $16.14 \pm 0.05 \times 10^{-6} \mathrm{~cm} / \mathrm{s}$ while the $\mathrm{P}_{\text {app }}$ of OE-ME was $26.99 \pm 0.45$ $\times 10^{-6} \mathrm{~cm} / \mathrm{s}, p=0.0571$. By calculating the sum of phenolic compounds concentration in the incubation media of both chambers, we estimate a recovery up to $80 \%$. The permeability coefficient of the ME was significantly higher than that of the unformulated OE.

Therefore, the formulation provided enhanced intestinal permeability of OE. This fact is probably due to the presence of surfactant used as a stabilizer of the internal phase. As previously reported, the surfactants enhance drug permeability in many ways, such as by increasing transcellular permeability and by inhibiting the efflux transport systems [70,71].

Moreover, non-ionic surfactants also contributed to increasing the contact time with the absorption site, and to increase endocytic and transcellular pathways by opening the tight junctions [72]. 
Many studies have been performed to elucidate the P-gp inhibition effect of Cremophor EL as well as other surfactants [73] and their mechanisms [74]. It was indicated that Cremophor EL and Transcutol may inhibit the function of P-gp by affecting membrane fluidity [40]. Cremophor could specifically bind to the hydrophobic domain of the P-gp that may change its secondary and/or tertiary structure and reduce its function [73]. Furthermore, the small dimensions of droplets of ME characterized by a big surface area increase solubility and absorption.

\section{Materials and Methods}

\subsection{Chemicals}

Ultrapure water was produced using the Milli-Q-system (Millipore SA, Molsheim, France). Acetonitrile of HPLC and HPLC-MS grades were from Panreac (Barcelona, Spain). Formic acid, hexane, and ethanol of analytical reagent grade were from Sigma-Aldrich (Steinheim, Germany). Standards of tyrosol ( $>99.5 \%$, Sigma-Aldrich, Steinheim, Germany) and rutin ( $>99 \%)$, luteolin-7-O-glucoside $(>98 \%)$, verbascoside ( $>99 \%)$, and oleuropein ( $>98 \%$ ) from Extrasynthese (Genay, France) were used for quantitative analysis.

Cremophor EL, Tween 80, and Phosphate buffered saline BioPerformance Certified pH 7.4 (PBS), were obtained from Sigma Aldrich (Saint Louis, MO, USA) with the support of Sigma Aldrich Italia (Milan, Italy). Soluplus ${ }^{\circledR}$ was a gift from BASF (Ludwigshafen, Germany) with the support of BASF Italia, BTC Chemical Distribution Unit (Cesano Maderno, Monza e Brianza, Italy). Captex 300, Captex 355, Labrasol ALF, Capryol 90, Transcutol HP, Labrafac, Labrafilm 1944, Labrafilm 2125, and Lauroglycol 90 were from Gattefossé (Saint Priest, France).

\subsection{Olive Samples and Preparation of the Phenolic Extract}

Samples of olive fruits (Olea europaea L.) from the Moraiolo cultivar were collected during the 2017 Summer before any stone lignification, particularly on the July 18th. Unripe olives were carry-on harvested from 10 selected plants in a farm located in Fiesole (Florence, Italy), which applied regular irrigation of orchards. About $1 \mathrm{~kg}$ of olives were picked along the whole circumference of the selected plants at a height of about $170 \mathrm{~cm}$. As soon as they arrived in the laboratory, olives were deep-frozen in liquid $\mathrm{N}_{2}$ and immediately freeze-dried. The mean weight of olives was $0.493 \mathrm{~g}$ per olive, while the moisture content, evaluated as the water lost during the lyophilization process, was $57 \%$. After lyophilization, the dried olives were minced in a laboratory miller (Zautec, Germany), thus obtaining about $430 \mathrm{~g}$ of a homogeneous olive powder.

Starting from this powdered material, a phenolic extract was prepared at laboratory scale as follow. Ten aliquots of $2.5 \mathrm{~g}$ of powder were weighted in plastic tubes and cold extracted twice with $40 \mathrm{~mL}$ of EtOH: $\mathrm{H}_{2} \mathrm{O}$ 80:20 $v / v$, homogenizing the mixture with ULTRA-TURRAX at $8117 \times g$ for $4 \mathrm{~min}$. The obtained mixture was cold centrifuged for $10 \mathrm{~min}$ at $1167 \times g$, and the recovered solution was defatted twice with $60 \mathrm{~mL}$ of hexane and then evaporated under vacuum. The dried extract was recovered with three aliquots of $16 \mathrm{~mL}, 8 \mathrm{~mL}$, and $4 \mathrm{~mL}$ of water and with the aid of ultrasounds. The obtained solution was then freeze-dried, thus obtaining a dried phenolic extract. The yield of the extract was $40 \%$ on the initial powder base, and thus we obtained a total of approx. $10 \mathrm{~g}$ of the extract.

The extract was characterized by HPLC-DAD: $50 \mathrm{mg}$ of dried extract were dissolved in $1 \mathrm{~mL}$ of $\mathrm{MeOH}: \mathrm{H}_{2} \mathrm{O} 50: 50 v / v$, and the obtained solution was used for the chromatographic analysis.

\subsection{HPLC-DAD Analysis}

For the chromatographic analysis, an HP1100 liquid chromatograph coupled with DAD detector was used (Agilent Technologies, Palo Alto, CA, USA) as previously described [52]. A Poroshell 120, EC-C18 (150 mm $\times 3.0 \mathrm{~mm}$ id, $2.7 \mu \mathrm{m}$; Agilent Technologies, Palo Alto, CA, USA) column coupled with a pre-column of the same phase, working at $26^{\circ} \mathrm{C}$, was used for separation of phenolic compounds. Elution was performed at a flow rate of $0.4 \mathrm{~mL} / \mathrm{min}$, using (A) acetonitrile and (B) $\mathrm{H}_{2} \mathrm{O}$ (pH 3.2 by 
formic acid) as solvents for the mobile phase, with the following multistep linear gradient: solvent A was increased from $5 \%$ to $40 \%$ in $40 \mathrm{~min}$, then remained at $40 \%$ for $5 \mathrm{~min}$, increased to $100 \%$ in $5 \mathrm{~min}$, and stayed at $100 \%$ for $3 \mathrm{~min}$, then returned to $5 \%$ in $2 \mathrm{~min}$. Total elution time of $55 \mathrm{~min}$, equilibration time $10 \mathrm{~min}$, injection volume, $2 \mu \mathrm{L}$. Chromatograms were recorded at 240, 280, and $330 \mathrm{~nm}$.

Quantification of phenolic compounds was carried out using 5 six-points calibration lines, built using hydroalcoholic solutions of tyrosol (linearity range $0-1.21 \mu \mathrm{g}, \mathrm{R}^{2}=0.9999$ ), oleuropein (linearity range $0-3.16 \mu \mathrm{g}, \mathrm{R}^{2}=0.9986$ ), luteolin-7-O-glucoside (linearity range $0-1.57 \mu \mathrm{g}, \mathrm{R}^{2}=0.9956$ ), rutin (linearity range $0-1.25 \mu \mathrm{g}, \mathrm{R}^{2}=0.9975$ ) and verbascoside (linearity range $0-1.96 \mu \mathrm{g}, \mathrm{R}^{2}=0.9996$ ). Limits of quantification (LOQ) were evaluated according to a previous study [75], using the above standards, and all the obtained values were lower than $0.1 \mathrm{mg} / \mathrm{kg}$. Tyrosol and hydroxytyrosol were expressed as $\mathrm{mg}_{\text {tyr }} \mathrm{kg}^{-1}$, rutin as $\mathrm{mg}_{\text {rut }} \mathrm{kg}^{-1}$, luteolin-7-O-glucoside as $\mathrm{mg}_{\text {lut }} \mathrm{kg}^{-1}$, verbascoside as $\mathrm{mg}_{\text {ver }} \mathrm{kg}^{-1}$, and oleuropein, comselogoside, and ligstroside as $\mathrm{mg}_{\mathrm{ole}} \mathrm{kg}^{-1}$. Finally, the total phenolic content was calculated as sum of the content of the previous phenolic compounds.

\subsection{Solubility Study}

The solubility of the powdered OE in different vehicles was evaluated by adding an excess of OE to $5 \mathrm{~mL}$ of each of the tested solvent/tenside: Water, Capryol 90, Captex 300, Captex 355, Labrafac, Labrafilm 1944, Labrafilm 2125, Labrasol ALF, Lauroglycol 90, Transcutol, and Cremophor EL. Each mixture of solvent and $\mathrm{OE}$ was stirred for $24 \mathrm{~h}$ at $25^{\circ} \mathrm{C}$, then it was centrifuged at $13,148 \times g$ for $10 \mathrm{~min}$. After removing the precipitate, the supernatant was diluted with $\mathrm{EtOH}$ and analyzed by HPLC-DAD to determine the concentration of the phenolic compounds from the OE. The analyses were performed in triplicate.

\subsection{Pseudo-Ternary Phase Diagram Construction}

The Chemix School (version 3.60, Arne Standnes, Norway) was used for constructing the pseudo-ternary phase diagram following the water titration method, in order to define the area of existence of the ME [76]. The selected surfactant and co-surfactant were mixed at various ratios $\left(S_{\text {mix }}\right)$, for each of which the pseudo-ternary phase diagram was built using different weight ratios oil-phase/ $S_{\text {mix }}$ : 0:100, 5:95, 10:90, 20:80, 30:70, 40:60, 50:50, 60:40, 70:30, 80:20, and 90:10. Each of the mixtures obtained using these different oil-phase $/ S_{\text {mix }}$ ratios were tested adding water dropwise to each blend, under vigorous stirring at room temperature. During water addition, the change in samples appearance was monitored to determine if transparent ME, emulsion, or gel was present.

\subsection{Solubility of the Olive Extract into the Microemulsion}

After the elaboration of a pseudo-ternary phase diagram, the maximum loading content of olive extract into the formulation was evaluated adding increasing amount of extract powder to the $\mathrm{ME}$ under stirring. The sample was gently stirred for $24 \mathrm{~h}$ at room temperature, protected from the light. Afterwards, excess extract was removed by centrifugation at $13,148 \times g$ for $10 \mathrm{~min}$ and the supernatant was analysed by HPLC after dilution with ethanol. The analyses were performed in triplicate.

\subsection{Characterization of Microemulsion}

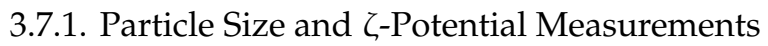

Droplet sizes of the developed ME were measured by a dynamic light scattering (DLS), Zsizer Nano series ZS90 (Malvern Instruments, Malvern, UK) equipped with a JDS Uniphase $22 \mathrm{~mW} H \mathrm{He}-\mathrm{Ne}$ laser operating at $632.8 \mathrm{~nm}$, an optical fiber-based detector, a digital LV/LSE-5003 correlator, and a temperature controller (Julabo water-bath) set at $25^{\circ} \mathrm{C}$. Time correlation functions were analysed to obtain the hydrodynamic diameter of the particles $(\mathrm{Zh})$ and the particle size distribution (polydispersity index, PdI) using the ALV-60 × 0 software V.3.X provided by Malvern. Autocorrelation functions were analysed by the Cumulants method, fitting a single exponential to the correlation function to obtain 
particle size distribution. Scattering was measured in an optical quality $4 \mathrm{~mL}$ borosilicate cell at a $90^{\circ}$ angle, diluting the samples in distilled water. $\zeta$-potential was measured using the same instrument; for all samples, an average of three measurements at stationary level was taken. The temperature was kept constant at $25^{\circ} \mathrm{C}$ by a Haake temperature controller. $\zeta$-potential was calculated from the electrophoretic mobility, using the Henry correction to Smoluchowski's equation.

\subsubsection{In Vitro Release Study}

The release studies of $\mathrm{OE}$ from ME in comparison to OE hydroalcoholic solution (EtOH: $\mathrm{H}_{2} \mathrm{O}$ 70:30) were carried out with the dialysis bag method (regenerated cellulose dialysis membranes, Spectrum Laboratories, Inc., Breda, The Netherlands, MWCO 12-14 kD). Two mL of the OE-ME or the solution were placed into dialysis membranes, sealed, and then immersed into $200 \mathrm{~mL}$ of the release medium at $37^{\circ} \mathrm{C}$ under magnetic stirring. Simulated gastric fluid (SGF, pH 1.2), simulated intestinal fluid (SIF pH 6.8), and PBS were used as release media. The composition of the gastric fluid was $2 \mathrm{~g}$ of $\mathrm{NaCl}$ and 7 $\mathrm{mL}$ of $\mathrm{HCl}$ per liter of deionized water. The intestinal fluid was composed of $6.805 \mathrm{~g}$ of $\mathrm{KH}_{2} \mathrm{PO}_{4}$ and $0.896 \mathrm{~g}$ of $\mathrm{NaOH}$ per liter of deionized water [77].

At predetermined time intervals, $1 \mathrm{~mL}$ of each release medium was withdrawn and replaced with equal volume of fresh solution. The total phenolic concentration in samples was finally determined by HPLC. All studies were performed in triplicate.

\subsection{Chemical and Physical Stability during Storage}

To estimate the shelf life, the OE-ME was stored in sealed glass containers at $4{ }^{\circ} \mathrm{C}$ for one month. Chemical and physical stabilities were checked periodically by monitoring transparency, phase separation, colour variation as the changes in particle size, homogeneity, $\zeta$-potential, and extract concentration by DLS and HPLC/DAD analyses.

\subsection{In Vitro Parallel Artificial Membrane Permeability Assay (PAMPA)}

The test was carried out in a 96-well, MultiScreen-IP PAMPA (Millipore corporation) filter plate. The ability of compounds to diffuse from a donor compartment into an acceptor compartment was evaluated, by placing a polyvinylidene difluoride (PVDF) membrane filter pretreated with a lipid-containing organic solvent between the two compartments. DMSO/PBS $(0.05 \mathrm{~mL} / \mathrm{mL}, \mathrm{pH} 7.4)$ mixture was used as receptor buffer. The artificial membrane added to each filter consisted of a combination of lecithin and cholesterol, $10 \mathrm{~g} / \mathrm{L}$ and $8 \mathrm{~g} / \mathrm{L}$, respectively, in 1,7-octadiene. Immediately after the deposition of the lipid solution $(5 \mu \mathrm{L}), 250 \mu \mathrm{L}$ of extract solution and OE-ME were added to each well of the donor plate. Each receptor plate was filled with $250 \mu \mathrm{L}$ of EtOH/PBS buffer. Afterwards, the donor plate was placed into the receptor plate, ensuring that the underside of the membrane was in contact with the buffer. The plate assembly was covered and incubated at room temperature for $2 \mathrm{~h}$.

Then, the samples were withdrawn, diluted with ethanol, centrifuged for $10 \mathrm{~min}$ at $13,148 \times g$, and the OE concentration was determined by HPLC. The $P_{e}(\mathrm{~cm} / \mathrm{s})$ was calculated according to the following equation:

$$
P_{e}=\frac{-\ln \left[1-\frac{C_{A t}}{C_{e q}}\right]}{A\left(\frac{1}{V_{D}}+\frac{1}{V_{A}}\right) t}
$$

where $\mathrm{A}$ is the active surface area $\left(0.3 \mathrm{~cm}^{2} \times\right.$ apparent porosity of the filter), $V_{D}$ and $V_{A}$ the well volume of the donor and acceptor plate $(\mathrm{mL})$, respectively, $\mathrm{t}$ the incubation time (s), and $C_{A t}$ and $C_{D t}$ the concentration of APP in the acceptor and donor plate at time $t$, respectively. $C_{e q}$ was calculated according to:

$$
C_{e q}=\frac{\left[C_{D t} \times V_{D}+C_{A t} \times V_{A}\right]}{V_{A}+V_{D}}
$$

The experiments were performed in quadruplicate. 


\subsection{MTS Assay for Cell Viability}

Viability analyses were performed using Cell Titer 96 Aqueous One solution cell proliferation (3-(4,5-dimethylthiazol-2-yl)-5-(3-carboxymethoxyphenyl)-2-(4-sulfophenyl)-2H-tetrazolium) (MTS) assay kit (Promega Madison, WI, USA). Briefly, Caco-2 cells were transferred to flat bottom 96-well tissue culture plates (Corning, NY, USA) at a seeding density of $5 \times 10^{3}$ cells/well and allowed to grow for $24 \mathrm{~h}$ under the conditions detailed above. For the MTS assay, the culture medium was removed and replaced with fresh medium containing OE-ME and the cells were incubated for 2 and $24 \mathrm{~h}$. Then the cells were exposed to MTS solution and allowed incubating for 2 and $24 \mathrm{~h}$ at $37^{\circ} \mathrm{C}$. The product of the reaction was measured at $490 \mathrm{~nm}$ using a spectrophotometer (Multilabel Counter 1240 Victor 3, Perkin Elmer, Milan, Italy). The cell death was expressed as a percentage of values obtained from control, untreated cells, calculated from three replicates of each ME dilution.

\subsection{Cell Culture for Transport Studies}

For transport studies, cells were seeded at 50,000 cells/well in cell, culture inserts with polyethylene terephthalate (PET) membranes (BRAND, Italy). Culture medium (DMEM) was added to apical (AP) and basolateral (BL) side and was replaced every day for the first week and daily thereafter. Cells were left to differentiate for 18-21 days.

\subsubsection{Monolayer Integrity}

The integrity of the layer was evaluated with the Lucifer Yellow (LY) permeability assay. LY was diluted in the transport buffer (Hank's Balanced Salt Solution, HBSS, with $\mathrm{Ca}^{2+}, \mathrm{Mg}^{2+}, 25 \mathrm{~m}$ M HEPES, $\mathrm{pH}$ 7.4) and added to the AP compartment at a final concentration of $100 \mu \mathrm{M}$. After incubation at $37^{\circ} \mathrm{C}$ for $1 \mathrm{~h}$, the HBSS in the BL chamber was collected, and the concentration of LY determined by using $485 \mathrm{~nm}$ excitation and $530 \mathrm{~nm}$ emission on a fluorescence plate reader (Multilabel Counter 1240 Victor 3, Perkin Elmer). The percentage of AP to BL permeability was calculated, according to the following equation:

$$
\% \text { permeability }=(\text { Fluorescence in the BL-blank }) /(\text { Fluorescence LY-blank }) * 100
$$

The critical maximum flux of LY to identify leaky monolayers was fixed to be less than $3 \%$ of starting concentration.

\subsubsection{Transport Experiments}

Transport studies were performed according to Hubatsch et al., (2007) [64]. Briefly, the culture medium (DMEM) was replaced with preheated $\left(37^{\circ} \mathrm{C}\right)$ transport HBSS medium supplemented with $25 \mathrm{mM}$ HEPES (pH 7.4). After that, the cell monolayer was equilibrated for $30 \mathrm{~min}$ at $37^{\circ} \mathrm{C}$. Caco-2 cells were then exposed for $2 \mathrm{~h}$ with OE-ME 1:100 or OE not formulated, in the apical (AP) chamber, while the basolateral (BL) chamber contained only HBSS.

At predetermined time intervals, $0.3 \mathrm{~mL}$ of medium in the BL side was taken for HPLC analyses and replaced with the same volume of fresh HBSS. At the end of the experiment, the integrity of the layer was re-evaluated with the LY permeability assay as described above.

The apparent permeability coefficient $\left(P_{a p p}, \mathrm{~cm} / \mathrm{s}\right)$ was calculated according to the following equation:

$$
P_{a p p}=V_{D} /\left(A \times M_{D}\right) \times\left(\Delta M_{R} / \Delta t\right)
$$

where: $V_{D}=$ apical (donor) volume $(\mathrm{mL}), M_{D}=$ apical (donor) amount, and $\Delta M_{R} / \Delta t=$ change in amount of compound in receiver compartment over time. 


\subsection{Statistical Analysis}

The experiments were performed at least in triplicate. The results of the quantitative analysis of $\mathrm{OE}$, the physicochemical characterization of ME and the in vitro tests were expressed as means $\pm \mathrm{SD}$ and analyzed by Mann-Whitney test. All analyses were carried out using GraphPad Prism 7.0 (GraphPad Software, San Diego, CA, USA). A $p$ value of 0.05 was considered significant.

\section{Conclusions}

A microemulsion intended for preparation of oral dosage form and suitable for delivering an $\mathrm{OE}$ was developed for the first time. The olive extract was obtained in the powder form from Tuscan olives of the Moraiolo cultivar harvested before any stone lignification and immediately lyophilized after freezing them with liquid nitrogen. It is characterized by a unique phytocomplex extremely rich in the phenolic compounds ligstroside, verbascoside, and particularly oleuropein, making it different from the commercial extracts obtained from olive leaves during the pruning period. Finally, the use of a well-characterized extract as a whole is economically advantageous and often more effective than the use of a single isolated component. A microemulsion is a formulation well suited to the delivery of not only single compounds, but also a phytocomplex. The microemulsion developed is suitable in terms of physico-chemical characteristics for oral administration and shows appropriate chemical and physical stability for over 30 days during storage at $4{ }^{\circ} \mathrm{C}$. ME has a good solubilizing effect on the olive extract, with a pronounced influence on its permeability, with respect to the unformulated extract. Caco-2 test confirmed PAMPA results and these in vitro assays revealed that the formulation increases the in vitro passive and active permeation of extract.

Author Contributions: Conceptualization, V.P., M.C.B., N.M., and L.C.; methodology, V.P. and N.M.; formal analysis, L.C., V.P., F.R., M.D., and C.L.; investigation, L.C., V.P., M.I., and C.L.; resources, N.M., C.L., and M.C.B.; data curation, L.C., V.P., F.R., G.V., M.D., and C.L.; writing-original draft preparation, L.C., V.P., M.C.B., C.L., and N.M.; writing-review and editing, L.C., M.I., C.L., and M.C.B.; supervision, N.M. and M.C.B.; project administration and funding acquisition, M.C.B., M.I., C.L., and N.M. All authors have read and agreed to the published version of the manuscript.

Funding: This research was partially funded with FEASR contribution (Rural Development Programm of the Tuscan Region, PIF 48/2017-mis. 16.2), Project Title: FIESOIL.

Acknowledgments: We thank MIUR-Italy ("Progetto Dipartimenti di Eccellenza 2018-2022" allocated to Department of Chemistry “Ugo Schiff”).

Conflicts of Interest: The authors declare no conflict of interest. The funders had no role in the design of the study; in the collection, analyses, or interpretation of data; in the writing of the manuscript, or in the decision to publish the results.

\section{References}

1. De Bock, M.; Hodgkinson, S.; Curtfield, W.; Schlothauer, R.C. Methods and Uses of an Extract from Olive Leaf in Management of Type 2 Diabetes. PCT Patent Application No. WO/2014/038962, 13 March 2014.

2. Giovannelli, L. Beneficial effects of olive oil phenols on the aging process: Experimental evidence and possible mechanisms of action. Nutr. Aging. 2013, 1, 207-223. [CrossRef]

3. Carpi, S.; Scoditti, E.; Massaro, M.; Polini, B.; De Caterina, R.; Nieri, P. The extra-virgin olive oil polyphenols oleocanthal and oleacein counteract inflammation-related gene and mirna expression in adipocytes by attenuating nf-kb activation. Nutrients 2019, 11, 2855. [CrossRef] [PubMed]

4. Romani, A.; Ieri, F.; Urciuoli, S.; Noce, A.; Marrone, G.; Nediani, C.; Bernini, R. Health effects of phenolic compounds found in extra-virgin olive oil, by-products, and leaf of Olea europaea L. Nutrients 2019, 11, 1776. [CrossRef]

5. Cecchi, L.; Migliorini, M.; Cherubini, C.; Innocenti, M.; Mulinacci, N. Whole lyophilized olives as source of unexpectedly high amounts of secoiridoids: The case of three Tuscan cultivars. J. Agric. Food Chem. 2015, 63, 1175-1185. [CrossRef] [PubMed]

6. Zanoni, B. Which processing markers are recommended for measuring and monitoring the transformation pathways of main components of olive oil? Ital. J. Food Sci. 2014, 26, 3-11. 
7. Morello, J.R.; Vuorela, S.; Romero, M.P.; Motilva, M.J.; Heinonen, M. Antioxidant activity of olive pulp and olive oil phenolic compound of the Arbequina cultivar. J. Agric. Food Chem. 2005, 53, 2002-2008. [CrossRef]

8. Ryan, D.; Antolovich, M.; Prenzler, P.D.; Robards, K.; Lavee, S. Biotransformation of phenolic compounds in Olea europaea L. Sci. Hortic. 2002, 92, 147-176. [CrossRef]

9. Ghanbari, R.; Anwar, F.; Alkharfy, K.M.; Gilani, A.H.; Saari, N. Valuable Nutrients and Functional Bioactives in Different Parts of Olive (Olea europaea L.) -A Review. Int. J. Mol. Sci. 2012, 13, 3291-3340. [CrossRef] [PubMed]

10. Omar, S.H. Oleuropein in olive and its pharmacological effects. Sci. Pharm. 2010, 78, 133-154. [CrossRef] [PubMed]

11. Ryan, D.; Robards, K.; Lavee, S. Changes in phenolic content of olive during maturation. J. Food Sci. Technol. 1999, 34, 265-274. [CrossRef]

12. Amiot, M.J.; Fleuriet, A.; Macheix, J.J. Importance and evolution of phenolic compounds in olive during grown and maturation. J. Agric. Food Chem. 1986, 34, 823-826. [CrossRef]

13. Amiot, M.J.; Fleuriet, A.; Macheix, J.J. Accumulation of oleuropein derivatives during olive maturation. Phytochemistry 1989, 28, 67-70. [CrossRef]

14. Kountouri, A.M.; Mylona, A.; Kaliora, A.C.; Andrikopoulos, N.K. Bioavailability of the phenolic compounds of the fruits (drupes) of Olea europaea (olives): Impact on plasma antioxidant status in humans. Phytomedicine 2007, 14, 659-667. [CrossRef] [PubMed]

15. Perrinjacquet-Moccetti, T.; Busjahn, A.; Schmidlin, C.; Schmidt, A.; Bradl, B.; Aydogan, C. Food Supplementation With an Olive (Olea Europaea, L.) Leaf Extract Reduces Blood Pressure in Borderline Hypertensive Monozygotic Twins. Phytother. Res. 2008, 22, 1239-1242. [CrossRef]

16. Garcia-Villalba, R.; Larrosa, M.; Possemiers, S.; Tomas-Barberan, F.A.; Espin, J.C. Bioavailability of phenolics from an oleuropein-rich olive (Olea europaea) leaf extract and its acute effect on plasma antioxidant status: Comparison between pre- and postmenopausal women. Eur. J. Nutr. 2014, 53, 1015-1027. [CrossRef] [PubMed]

17. Hornedo-Ortega, R.; Cerezo, A.B.; de Pablos, R.M.; Krisa, S.; Richard, T.; Garcia-Parrilla, M.C.; Troncoso, A.M. Phenolic compounds characteristic of the Mediterranean Diet in mitigating microglia-mediated neuroinflammation. Front. Cell. Neurosci. 2018, 12, 373. [CrossRef] [PubMed]

18. Alipieva, K.; Korkina, L.; Orhan, I.E.; Georgiev, M.I. Verbascoside-A review of its occurrence, (bio)synthesis and pharmacological significance. Biotechnol. Anal. 2014, 32, 1065-1076. [CrossRef] [PubMed]

19. Funes, L.; Fernandez-Arroyo, S.; Laporta, O.; Pons, A.; Roche, E.; Segura-Carretero, A.; Fernandez-Gutierrez, A.; Micol, V. Correlation between plasma antioxidant capacity and verbascoside levels in rats after oral administration of lemon verbena extract. Food Chem. 2009, 117, 589-598. [CrossRef]

20. Attia, Y.M.; El-Kersh, D.M.; Wagdy, W.A.; Elmazar, M.M. Verbascoside: Identification, Quantification, and Potential Sensitization of Colorectal Cancer Cells to 5-FU by Targeting PI3K/AKT Pathway. Sci. Rep. 2018, 8, 16939. [CrossRef]

21. Zhang, Y.; Yuan, Y.; Wu, H.; Xie, Z.; Wu, Y.; Song, X.; Wang, J.; Shu, W.; Xu, J.; Liu, B.; et al. Effect of verbascoside on apoptosis and metastasis in human oral squamous cell carcinoma. Int. J. Cancer 2018, 143, 980-991. [CrossRef]

22. Garro, H.A.; Bruna-Haupt, E.; Cianchino, V.; Malizia, F.; Favier, S.; Menacho-Márquez, M.; Cifuente, D.; Fernández, C.O.; Pungitore, C.R. Verbascoside, synthetic derivatives and other glycosides from Argentinian native plant species as potential antitumoral agents. Nat. Prod. Res. 2020, in press. [CrossRef] [PubMed]

23. Reid, A.M.; Juvonen, R.; Huuskonen, P.; Lehtonen, M.; Pasanen, M.; Lall, N. In Vitro human metabolism and inhibition potency of verbascoside for CYP enzymes. Molecules 2019, 24, 2191. [CrossRef]

24. Grewal, R.; Reutzel, M.; Dilberger, B.; Hein, H.; Zotzel, J.; Marx, S.; Tretzel, J.; Sarafeddinov, A.; Fichs, C.; Eckert, G.P. Purified oleocanthal and ligstroside protect against mitochondrial dysfunction in models of early Alzheimer's disease and brain ageing. Exp. Neurol. 2020, 328, 113248. [CrossRef] [PubMed]

25. Williamson, E.M. Synergy and other interactions in phytomedicins. Phytomedicins 2001, 8, 401-409. [CrossRef]

26. Lee, O.H.; Lee, B.Y. Antioxidant and antimicrobial activities of individual and combined phenolics in Olea europaea leaf extract. Bioresour. Technol. 2010, 101, 3751-3754. [CrossRef]

27. Cecchi, L.; Guerrini, L.; Bellumori, M.; Balli, D.; Xie, P.; Parenti, A.; Mulinacci, N. Optimization of the production process of dried unripe olives (Olea europaea L.) as a nutraceutical ingredient naturally rich in phenolic compounds. Lwt Food Sci. Technol. 2020, 129, 109569. [CrossRef] 
28. Serra, A.; Rubiò, L.; Borràs, X.; Macià, A.; Romero, M.P.; Motilva, M.J. Distribution of olive oil phenolic compounds in rat tissues after administration of a phenolic extract from olive cake. Mol. Nutr. Food Res. 2012, 56, 486-496. [CrossRef] [PubMed]

29. Domínguez-Perles, R.; Auñón, D.; Ferreres, F.; Gil-Izquierdo, A. Physiological linkage of gender, bioavailable hydroxytyrosol derivatives, and their metabolites with systemic catecholamine metabolism. Food Funct. 2017, 8, 4570-4581. [CrossRef]

30. Ali, A.; Ahmad, U.; Akhtar, J.; Khan, M.M. Engineered nano scale formulation strategies to augment efficiency of nutraceuticals. J. Funct. Foods 2019, 62, 103554. [CrossRef]

31. Bilia, A.R.; Piazzini, V.; Guccione, C.; Risaliti, L.; Asprea, M.; Capecchi, G.; Bergonzi, M.C. Improving on nature: The role of nanomedicine in the development of clinical natural drugs. Planta Med. 2017, 83, 366-381. [CrossRef]

32. Bilia, A.R.; Piazzini, V.; Risaliti, L.; Vanti, G.; Casamonti, M.; Wang, M.; Bergonzi, M.C. Nanocarriers: A Successful Tool to Increase Solubility, Stability and Optimise Bioefficacy of Natural Constituents. Curr. Med. Chem. 2018, 25, 1-24. [CrossRef] [PubMed]

33. Bonechi, C.; Donati, A.; Tamasi, G.; Pardini, A.; Rostom, H.; Leone, G.; Lamponi, S.; Consumi, M.; Magnani, A.; Rossi, C. Chemical characterization of liposomes containing nutraceutical compounds: Tyrosol, hydroxytyrosol and oleuropein. Biophys. Chem. 2019, 246, 25-34. [CrossRef] [PubMed]

34. Yuan, J.J.; Qin, F.G.F.; Tu, J.L.; Li, B. Preparation, Characterization, and Antioxidant Activity Evaluation of Liposomes Containing Water-Soluble Hydroxytyrosol from Olive. Molecules 2017, 22, 870. [CrossRef] [PubMed]

35. Chatzidaki, M.D.; Arik, N.; Monteil, J.; Papadimitriou, V.; Leal-Calderon, F.; Xenakis, A. Microemulsion Versus Emulsion as Effective Carrier of Hydroxytyrosol. Colloids Surf B Biointerfaces 2016, 137, 146-151. [CrossRef] [PubMed]

36. Guan, Q.; Sun, S.; Li, X.; Lv, S.; Xu, T.; Sun, J.; Feng, W.; Zhang, L.; Li, Y. Preparation, in vitro and in vivo evaluation of mPEG-PLGA nanoparticles co-loaded with syringopicroside and hydroxytyrosol. J. Mater. Sci. Mater. Med. 2016, 27. [CrossRef]

37. Mohammadi, A.; Jafari, S.M.; Assadpour, E.; Esfanjani, A.F. Nano-encapsulation of olive lead phenolic compounds through WPC-pectin complexes and evaluating their release rate. Int. J. Biol. Macromol. 2016, 82, 816-822. [CrossRef]

38. Porter, C.J.H.; Trevaskis, N.L.; Charman, W.N. Lipids and lipid-based formulations: Optimizing the oral delivery of lipophilic drugs. Nat. Rev. Drug Discov. 2007, 6, 231-248. [CrossRef]

39. Porter, C.J.H.; Pouton, C.W.; Cuine, J.F.; Charman, W.N. Enhancing intestinal drug solubilisation using lipid-based delivery systems. Adv. Drug Deliv. Rev. 2008, 60, 673-691. [CrossRef]

40. Yin, Y.-M.; Cui, F.-D.; Mu, C.-F.; Choi, M.-K.; Kim, J.S.; Chung, S.-J.; Shim, C.-K.; Kim, D.-D. Docetaxel microemulsion for enhanced oral bioavailability: Preparation and in vitro and in vivo evaluation. J. Control. Rel. 2009, 140, 86-94. [CrossRef]

41. Rege, B.D.; Kao, J.P.Y.; Polli, J.E. Effects of nonionic surfactants on membrane transporters in Caco-2 cell monolayers. Eur. J. Pharm. Sci. 2002, 16, 237-246. [CrossRef]

42. Takahashi, Y.; Kondo, H.; Yasuda, T.; Watanabe, T.; Kobayashi, S.-I.; Yokohama, S. Common solubilizers to estimate the Caco-2 transport of poorly water-soluble drugs. Int. J. Pharm. 2002, 246, 85-94. [CrossRef]

43. Lin, Y.L.; Shen, Q.; Katsumi, H.; Okada, N.; Fujita, T.; Jiang, X.H.; Yamamoto, A. Effects of Labrasol and other pharmaceutical excipients on the intestinal transport and absorption of rhodamine123, a P-glycoprotein substrate, in rats. Biol. Pharm. Bull. 2007, 30, 1301-1307. [CrossRef] [PubMed]

44. Lea, T. Caco-2 cell line. In The Impact of Food Bioactives on Health; Springer International Publishing: Cham, Switzerland, 2015; pp. 103-111.

45. Piazzini, V.; Rosseti, C.; Bigagli, E.; Luceri, C.; Bilia, A.R.; Bergonzi, M.C. Prediction of permeation and cellular transport of Silybum marianum extract formulated in a nanoemulsion by using PAMPA and Caco-2 cell models. Planta Med. 2017, 83, 1184-1193. [CrossRef]

46. Piazzini, V.; D’Ambrosio, M.; Luceri, C.; Cinci, L.; Landucci, E.; Bilia, A.R.; Bergonzi, M.C. Formulation of Nanomicelles to Improve the Solubility and the Oral Absorption of Silymarin. Molecules 2019, 24, 1688. [CrossRef] [PubMed] 
47. Kansy, M.; Senner, F.; Gubernator, K. Physicochemical high throughput screening: Parallel artificial membrane permeation assay in the description of passive absorption processes. J. Med. Chem. 1998, 41, 1007-1010. [CrossRef] [PubMed]

48. Bergonzi, M.C.; Hamdouch, R.; Mazzacuva, F.; Isacchi, B.; Bilia, A.R. Optimization, characterization and in vitro evaluation of curcumin microemulsions. LWT Food Sci. Technol. 2014, 59, 148-155. [CrossRef]

49. Piazzini, V.; Monteforte, E.; Luceri, C.; Bigagli, E.; Bilia, A.R.; Bergonzi, M.C. Nanoemulsion for improving solubility and permeability of Vitex aguns-castus extract: Formulation and in vitro evaluation using PAMPA and Caco-2 approaches. Drug Deliv. 2017, 24, 380-390. [CrossRef]

50. Navarro del Hierro, J.; Piazzini, V.; Reglero, G.J.; Martin, D.; Bergonzi, M.C. In vitro permeability of saponins and sapogenins from seed extracts by the parallel artificial membrane permeability assay (PAMPA): Effect of in vitro gastrointestinal digestion. J. Agric. Food Chem. 2020, 68, 1297-1305. [CrossRef]

51. Piazzini, V.; Vasarri, M.; Degl'Innocenti, D.; Guastini, A.; Barletta, E.; Salvatici, M.C.; Bilia, A.R.; Bergonzi, M.C. Nanoformulations of Posidonia oceanica to inhibit human neuroblastoma cell migration. Pharmaceutics 2019, 11, 655. [CrossRef]

52. Cecchi, L.; Migliorini, M.; Zanoni, B.; Breschi, C.; Mulinacci, N. An effective HPLC-based approach for the evaluation of the content of total phenolic compounds transferred from olives to virgin olive oil during the olive milling process. J. Sci. Food Agric. 2018, 98, 3636-3643. [CrossRef]

53. Cecchi, L.; Bellumori, M.; Cipriani, C.; Mocali, A.; Innocenti, M.; Mulinacci, N.; Giovannelli, L. A two-phase olive mill by-product (pâté) as a convenient source of phenolic compounds: Content, stability, and antiaging properties in cultured human fibroblasts. J. Funct. Foods 2018, 40, 751-759. [CrossRef]

54. Benincasa, C.; Santoro, I.; Nardi, M.; Cassano, A.; Sindona, G. Eco-Friendly Extraction and Characterisation of Nutraceuticals from Olive Leaves. Molecules 2019, 24, 3481. [CrossRef] [PubMed]

55. Dalla Rosa, A.; Junges, A.; Fernandes, I.A.; Cansian, R.L.; Corazza, M.L.; Franceschi, E.; Backes, G.T.; Valduga, E. High pressure extraction of olive leaves (Olea europaea): Bioactive compounds, bioactivity and kinetic modelling. J. Food Sci. Technol. 2019, 56, 3864-3876. [CrossRef] [PubMed]

56. Amidzic, M.; Maric, P.; Fumic, B.; Petlevski, R.; Bljajic, K.; Koncic, M.Z. Oleuropein-Rich Olive Leaf Extracts May Ameliorate Consequences of Glucose-Induced Oxidative Stress in Hep G2 Cells. Nat. Prod. Commun. 2018, 13. [CrossRef]

57. Somerville, V.; Moore, R.; Braakhuis, A. The Effect of Olive Leaf Extract on Upper Respiratory Illness in High School Athletes: A Randomised Control Trial. Nutrients 2019, 11, 358. [CrossRef] [PubMed]

58. Xie, P.-J.; Huang, L.-X.; Zhang, C.-H.; You, F.; Zhang, Y.-L. Reduced pressure extraction of oleuropein from olive leaves (Olea europaea L.) with ultrasound assistance. Food Bioprod. Process. 2015, 93, 29-38. [CrossRef]

59. Wang, X.; Huang, L.; Zhang, C.; Xie, P.; Deng, Y.; Liu, L. Preparation and Physicochemical Properties of Olive Leaf Extract. Chem. Ind. For. Prod. 2019, 39, 83-90. [CrossRef]

60. Xie, P.-J.; Huang, L.-X.; Zhang, C.-H.; You, F.; Wang, C.-Z.; Zhang, Y.-L. Reduced-pressure boiling extraction of oleuropein coupled with ultrasonication from olive leaves (Olea europaea L.). Adv. Mater. Sci. Eng. 2015, 719485. [CrossRef]

61. Borhade, V.; Pathak, S.; Sharma, S.; Patravale, V. Clotrimazole nanoemulsion for malaria chemotherapy. Part I: Preformulation studies, formulation design and physicochemical evaluation. Int. J. Pharm. 2012, 431, 138-148. [CrossRef]

62. Shakeel, F.; Haq, N.; Alanazi, F.K.; Alsarra, I.A. Impact of various nonionic surfactants on self-nanoemulsification efficiency of two grades of Capryol (Capryol-90 and Capryol-PGMC). J. Mol. Liq. 2013, 182, 57-63. [CrossRef]

63. Win, K.Y.; Feng, S.S. Effects of particle size and surface coating on cellular uptake of polymeric nanoparticles for oral delivery of anticancer drugs. Biomaterials 2005, 26, 2713-2722. [CrossRef]

64. Piazzini, V.; Cinci, L.; D’Ambrosio, M.; Luceri, C.; Bilia, A.R.; Bergonzi, M.C. SLNs and Chitosan-coated SLNs as promising tool for silybin delivery: Formulation, characterization, and in vitro evaluation. Curr. Drug Deliv. 2018, 16, 142-152. [CrossRef] [PubMed]

65. Piazzini, V.; Micheli, L.; Luceri, C.; D’Ambrosio, M.; Cinci, L.; Ghelardini, C.; Bilia, A.R.; Di Cesare Mannelli, L.; Bergonzi, M.C. Nanostructured lipid carriers for oral delivery of silymarin: Improving the absorption and in vivo efficacy in type 2 diabetes and metabolic syndrome. Int. J. Pharm. 2019, 572, 118838. [CrossRef] [PubMed] 
66. Hubatsch, I.; Ragnarsson, E.G.; Artursson, P. Determination of drug permeability and prediction of drug absorption in Caco-2 monolayers. Nat. Protoc. 2007, 2, 2111-2119. [CrossRef] [PubMed]

67. Makhey, V.D.; Guo, A.; Norris, D.A.; Hu, P.; Yan, J.; Sinko, P.J. Characterization of the regional intestinal kinetics of drug efflux in rat and human intestine and in Caco-2 cells. Pharm. Res. 1998, 15, 1160-1167. [CrossRef]

68. Piazzini, V.; Lemmi, B.; D’Ambrosio, M.; Cinci, L.; Luceri, C.; Bilia, A.R.; Bergonzi, M.C. Nanostructured Lipid Carriers as Promising Delivery Systems for Plant Extracts: The Case of Silymarin. Appl. Sci. 2018, 8, 1163. [CrossRef]

69. Iacomino, G.; Fierro, O.; D'Auria, S.; Picariello, G.; Ferranti, P.; Liguori, C.; Addeo, F.; Mamone, G. Structural analysis and Caco-2 cell permeability of the celiac-toxic A-gliadin peptide 31-55. J. Agric. Food Chem. 2013, 61, 1088-1096. [CrossRef]

70. Seljak, K.B.; Berginc, K.; Trontelj, J.; Zvonar, A.; Kristl, A.; Gašperlin, M. A self-microemulsifying drug delivery system to overcome intestinal resveratrol toxicity and presystemic metabolism. J. Pharm. Sci. 2014, 103, 3491-3500. [CrossRef]

71. Bergamante, V.; Ceschel, G.C.; Marazzita, S.; Ronchi, C.; Fini, A. Effect of vehicles on topical application of Aloe vera and Arnica montana components. Drug Deliv. 2007, 14, 427-432. [CrossRef]

72. Sha, X.; Yan, G.; Wu, Y.; Li, J.; Fang, X. Effect of self-microemulsifying drug delivery systems containing Labrasol on tight junctions in Caco-2 cells. Eur. J. Pharm. Sci. 2005, 24, 477-486. [CrossRef]

73. Nerurkar, M.M.; Burton, P.S.; Borchardt, R.T. The use of surfactants to enhance the permeability of peptides through Caco-2 cells by inhibition of an apically polarized efflux system. Pharm. Res. 1996, 13, 528-534. [CrossRef] [PubMed]

74. Shono, Y.; Nishihara, H.; Matsuda, Y.; Furukawa, S.; Okada, N.; Fujita, T.; Yamamoto, A. Modulation of intestinal P-glycoprotein function by Cremophor EL and other surfactants by an in vitro diffusion chamber method using the isolated rat intestinal membranes. J. Pharm. Sci. 2004, 93, 877-885. [CrossRef] [PubMed]

75. Cecchi, L.; Innocenti, M.; Urciuoli, S.; Arlorio, M.; Paoli, P.; Mulinacci, N. In depth study of phenolic profile and PTP-1B inhibitory power of cold-pressed grape seed oils of different varieties. Food Chem. 2019, 271, 380-387. [CrossRef]

76. Lawrence, M.J.; Rees, G.D. Microemulsion-based media as novel drug delivery systems. Adv. Drug. Deliv. Rev. 2000, 45, 89-121. [CrossRef]

77. United States Pharmacopeia and National Formulary, 25th ed.; United States Pharmacopeial Convention Inc.: Rockville, MD, USA, 2002.

Sample Availability: Samples of the compounds are not available from the authors.

(C) 2020 by the authors. Licensee MDPI, Basel, Switzerland. This article is an open access article distributed under the terms and conditions of the Creative Commons Attribution (CC BY) license (http://creativecommons.org/licenses/by/4.0/). 